\title{
Diferentes substratos na formação de mudas de biribazeiro (Rollinia mucosa [Jacq.] Bail) em Humaitá, AM
}

\author{
Different substrates in the formation of biribazeiro muds (Rollinia mucosa [Jacq.] Bail) in
} Humaitá, AM

\author{
A. F. L. de Lima1; M. C. C. Campos ${ }^{2 *}$; E. G. de Brito Filho²; E. L. Simões ${ }^{2}$; J. M. \\ da Cunha'; ; D. M. P. da Silva ${ }^{2}$; F. P. de Oliveira ${ }^{3}$; L.A.C. dos Santos ${ }^{2}$ \\ ${ }^{1}$ Universidade Federal do Amazonas, 69800-000, Humaitá-Amazonas, Brasil \\ ${ }^{2}$ Universidade Federal do Amazonas, Instituto de Educação Agricultura e Ambiente, 69800-000, Humaitá-Amazonas, \\ Brasil
}

${ }^{3}$ Universidade Federal da Paraiba, 58397-000, Areia-Paraiba, Brasil

*mcesarsolos@gmail.com

(Recebido em 09 de outubro de 2019; aceito em 15 de julho de 2020)

\begin{abstract}
$\mathrm{O}$ trabalho objetivou avaliar os efeitos de diferentes substratos na formação de mudas de biribazeiro. $\mathrm{O}$ biribazeiro é uma planta de origem amazônica, pertencente à família das anonáceas, cultivada principalmente em pomares domésticos, devido ao seu sabor adocicado. O experimento foi conduzido no município de Humaitá - AM, utilizando o delineamento experimental em blocos casualizado, contendo quatro blocos, com sete tratamentos, quanto a diferentes formulações de substratos, utilizando solo, húmus, compostagem e areia. Foram realizadas medições das variáveis: diâmetro do caule; número de folhas; altura; massa seca e fresca da raiz e da parte aérea; e comprimento de raiz, relação entre a altura da parte aérea e o diâmetro do caule e índice de qualidade Dickson. Os melhores resultados foram obtidos com o tratamento 4 utilizando $50 \%$ de solo e $50 \%$ de húmus. O tratamento 7 utilizando $25 \%$ de solo $50 \%$ de compostagem e $25 \%$ de areia apresentou deficiência de $\mathrm{K}$, causando clorose e necrose nas plantas, não propiciando crescimento satisfatório. O húmus apresentou maiores teores de macro e micronutrientes em relação a compostagem.

Palavras-chave: crescimento de mudas, composto orgânico, nutrientes.
\end{abstract}

The objective of this work was to evaluate the effects of different substrates in the formation of saplings. The biribazeiro is a plant of Amazonian origin, belonging to the family of the anonáceas, cultivated mainly in domestic orchards, due to its sweetish flavor. The experiment was conducted in the municipality of Humaitá - AM, Brazil, using a randomized blocks design, containing four blocks, with seven treatments for different substratum formulations, using soil, humus, compost and sand. Measurements were made of the shavings: stem diameter; number of leaves; height; fresh and dry root and shoot mass; and root length, after obtaining these data the relation between shoot height and stem diameter and also Dickson quality index was calculated. The best results for all evaluated variables were obtained with treatment 4 using $50 \%$ of soil and $50 \%$ of humus. The treatment 7 using $25 \%$ of soil $50 \%$ of compost and $25 \%$ of sand presented $\mathrm{K}$ deficiency, causing chlorosis and necrosis in the plants, not propitiating satisfactory growth. Humus presented higher macro and micronutrient contents in relation to composting.

Keywords: growth of seedlings, organic compound, nutrients.

\section{INTRODUÇÃO}

O biribazeiro (Rollinia mucosa [Jacq.] Bail) é uma planta frutífera, de ocorrência silvestre nos trópicos, pertencente à família, Annonaceae [1]. Estima-se que, a família annonaceae possua 129 gêneros e 2.100 espécies. O Brasil possui 29 gêneros registrados, incluindo os de maior importância comercial, como é o caso da graviola (Annona muricata L.), fruta do conde (Annona squamosa L.), cherimóia (Annona cherimólia [Mill.]) e o biribá (Rollinia mucosa) [2]. O fruto do biribazeiro é do tipo sincarpo cônico, composto por diversas partes hexagonais, muito unidas. Quando maduro pode pesar até $1,3 \mathrm{~kg}$, apresenta coloração amarela, sabor adocicado, aroma agradável, coloração da polpa variando de esbranquiçada a creme. Ele apresenta muitas sementes com cor escura. Devido essas características o fruto tem grande aceitação, sendo consumido em sua maioria in natura [3]. 
Além disso, o biribazeiro por ser uma espécie nativa dos trópicos, tem importância, em reflorestamento e paisagismos [4].

Umas das etapas importantes para o sucesso de um pomar ou reflorestamento, é a produção das mudas, que devem ter qualidade e vigor assegurando o bom desenvolvimento no campo [5] o que envolve o suprimento de nutrientes tanto em quantidades quanto em qualidade às plantas [6]. Por outro lado, para que isso aconteça, o substrato deve ser adequado, para o que se tenha maior crescimento das raízes. Para isso, ele deve apresentar baixa densidade, boa capacidade de absorção e retenção de água, boa aeração e drenagem, ser isento de pragas, doenças, substâncias tóxicas e propágulo de plantas daninhas $[5,7]$.

Com a crescente produção de resíduos agroindustriais do beneficiamento do açaí, da pecuária e das madeireiras, há a preocupação com a contaminação do meio ambiente, devido o descarte incorreto [8]. Assim, há a necessidade de alternativas para o uso desses resíduos, dentre essas, se vislumbra o uso desses na agricultura [9], sendo um dos destinos a formulação de compostagem e/ou húmus para composição de substrato na produção de mudas, minimizando assim o risco de contaminação do meio ambiente.

Sendo o biribazeiro uma planta apreciada por apresentar o fruto com sabor adocicado e as mudas utilizadas como porta enxertos para outras anonáceas de maior valor comercial por ser resistente a podridão-da-raiz e a broca do colo [4], é de suma importância estudos avaliando diferentes formulações de substratos para produção de mudas. Diante disto, objetivou-se, avaliar os efeitos de diferentes substratos na formação de mudas de biribazeiro (Rollinia mucosa [Jacq.] Baill) (Annonaceae) em Humaitá, AM.

\section{MATERIAL E MÉTODOS}

O estudo foi conduzido no município de Humaitá, sul do Amazonas, na casa de vegetação do Instituto de Educação, Agricultura e Ambiente - IEAA/UFAM (7³0'54.03"S, 6301'41.35"O), altitude média de 90 metros. Segundo a classificação de Köppen, a zona climática da região pertence ao grupo A (Clima Tropical Chuvoso) e tipo climático Am (chuvas do tipo monção), apresentando um período seco de pequena duração (mês de junho), com precipitação anual variando de 2.250 a $2.750 \mathrm{~mm}$. A temperatura média anual varia de 24 a $26^{\circ} \mathrm{C}$ e a umidade relativa do ar varia de 85 a $90 \%$ [10].

As sementes de biribazeiro foram obtidas de frutos colhidos em propriedade particulares localizadas no município de Porto Velho - RO. Estas foram extraídas de forma manual, com auxílio de peneira para retirada da polpa e colocadas para secar à sombra por 72 horas, as mesmas foram semeadas no dia 17/03/2017, em sementeira com areia de tamanho menor que $1 \mathrm{~mm}$, onde foram semeadas a $1,5 \mathrm{~cm}$ de profundidade com espaçamento de $2,5 \times 2,5 \mathrm{~cm}$ entre sementes, com regas diárias para promover a germinação. A germinação iniciou 19 dias após a semeadura e, quando atingiram uma taxa de germinação de $50 \%$ e as plântulas (três folhas verdadeiras), foram selecionadas as plântulas de tamanho homogêneo e transplantadas para sacos de polietileno de 2 litros $(16,50$ x 23,00 cm) contendo as diferentes formulações de substratos.

Para a compostagem foram formadas leiras com $50 \%$ de caroço de açaí inteiro, $40 \%$ de esterco bovino e $10 \%$ serragem. No preparo os materiais foram distribuídos em camadas uniformes e umedecido até atingir de 50 a $60 \%$ de umidade. A oxigenação da leira foi controlada pelo revolvimento manual. O ciclo de revolvimento foi de duas vezes por mês, permitindo o bom arejamento da massa em decomposição e o controle da temperatura.

Na produção de húmus foi utilizada a vermicompostagem, esse processo consistiu em colocar parte da compostagem em fase de maturação, em minhocários artesanais, juntamente com as minhocas da espécie Eisenia foetida. Os minhocários receberam água diariamente, juntamente com restos de legumes e outros alimentos duas vezes por semana. Após o período de decomposição do material, que levou em torno de 90 dias foi separado o húmus das minhocas através de peneiramento.

Em casa de vegetação, o delineamento experimental utilizado foi em blocos casualizados, com sete tratamentos, quatro blocos e três repetições (Tabela 1). Utilizou-se seis formulações de substratos e um tratamento contendo apenas solo coletado, cada tratamento utilizou diferentes proporções de solo, húmus, compostagem e areia de tamanho menor $1 \mathrm{~mm}$. 
Tabela 1: Tabela contendo os diferentes tratamentos com suas respectivas formulações.

\begin{tabular}{ccccc}
\hline Tratamentos & Solo & Húmus & Compostagem & Areia \\
\hline T 1 & $100 \%$ & - & - & - \\
T 2 & $50 \%$ & $25 \%$ & - & $25 \%$ \\
T 3 & $50 \%$ & - & $25 \%$ & $25 \%$ \\
T 4 & $50 \%$ & $50 \%$ & - & - \\
T 5 & $50 \%$ & - & $50 \%$ & - \\
T 6 & $25 \%$ & $50 \%$ & - & $25 \%$ \\
T 7 & $25 \%$ & - & $50 \%$ & $25 \%$ \\
\hline
\end{tabular}

As avaliações das plantas iniciaram aos 80 dias após semeadura, sendo os parâmetros mensurados a cada 14 dias: Diâmetro do Caule (DC) com auxilio de um paquímetro digital expresso em mm; Número de Folhas (NF) computado de modo manual; e Altura $(\mathrm{H})$ com auxílio de uma régua graduada em $\mathrm{cm}$, onde mediu-se a distância entre o colo da muda até o meristema apical caulinar.

Decorridos 150 dias após a semeadura foram mensuradas as seguintes características biométricas das mudas: DC; NF; H; Comprimento de Raiz (CR) com auxílio de uma régua graduada em $\mathrm{cm}$, onde mediu-se a distância do colo da planta até ápice da raiz principal; Massas Frescas da Parte Aérea (MFPA), do sistema radicular (MFR) foram mensuradas em balança digital após lavagem das mudas em água corrente e suas respectivas Massas Secas (MSPA, MSR) após a secagem em estufa com circulação de ar a $60^{\circ} \mathrm{C}$, por 72 horas, sendo os resultados de ambas, expresso em $\mathrm{g}$ plântula ${ }^{-1}$.

Além das características supracitadas, também foram calculados a relação entre altura da parte aérea e diâmetro do caule (H/DC) e o Índice de Qualidade de Dickson (IQD) de acordo com a proposta de Dickson et al. (1960) [11], equação (1).

$\mathrm{IQD}=\mathrm{MST} /[(\mathrm{H} / \mathrm{DC})+(\mathrm{MSPA} / \mathrm{MSR})]$

sendo:

ÍQD = índice de qualidade de Dickson;

MST $=$ massa seca total $($ MST $=$ MSPA+MSR);

$\mathrm{H}=$ altura;

$\mathrm{DC}=$ diâmetro do caule;

MSPA = massa seca da parte aérea;

MSR $=$ massa seca da raiz.

Os dados obtidos foram submetidos à análise de variância e as médias foram comparadas pelo teste de Tukey a 5\% de probabilidade (p>0,5), utilizando o software estatístico ASSISTAT 7.7. [12].

\section{RESULTADOS E DISCUSSÃO}

A Tabela 2 apresenta a caracterização dos atributos químicos e da textura do solo coletado. De acordo com Ribeiro et al. (1999) [13], a acidez do solo é classificada como boa para o pH, com teores muito baixo de $\mathrm{Al}^{3+}$ e alto teor de $\mathrm{H}+\mathrm{Al}$, em relação aos macronutrientes o solo apresenta teores classificados em baixo para $\mathrm{K}^{+}$, bom para $\mathrm{P}$ e $\mathrm{Mg}^{2+}$ e muito bom para $\mathrm{Ca}^{2+}$. A SB, t e T, apresentaram classificação de muito bom, o composto orgânico $(\mathrm{CO})$ foi classificado como grupamento textural médio com classe textural franco-argilo-arenosa. De acordo com a classificação, o solo apresentou V\% médio caracterizando um solo distrófico, necessitando de uma adubação com $\mathrm{K}^{+}$. 
Tabela 2: Caracterização física e química do solo utilizado para formulação do substrato em Humaitá, AM.

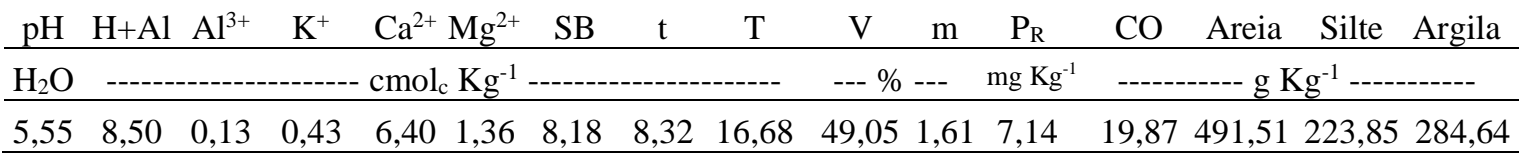

COT: carbono orgânico total.

O húmus apresentou maiores teores de macronutrientes em relação a compostagem (Tabela 3), isso ocorreu em função da ação detritívora das minhocas e da microflora presente no trato digestivo que digere material orgânico, reduzindo o seu tamanho em cerca de $25 \%$, disponibilizando mais os nutrientes $[14,15]$.

De modo geral, observa-se que substrato contendo húmus apresentaram os teores mais regulares para todos os nutrientes, tendo um fornecimento mais uniforme, isso provavelmente contribuiu para melhor desempenho das mudas nestes substratos, visto que estes nutrientes são requeridos em maiores quantidades para o ótimo crescimento das plantas [16].

Podemos observar na Tabela 3 que os dois compostos apresentaram maiores teores de macro e micronutrientes do que apresentado por Erlacher et al. (2017) [8], que avaliou o uso de caroço de açaí para formulação de substratos na produção de mudas de hortaliças.

Tabela 3: Caracterização química dos compostos orgânicos utilizados nos substratos em Humaitá, AM.

\begin{tabular}{|c|c|c|c|c|c|c|c|c|c|c|c|c|c|c|c|c|}
\hline \multirow{2}{*}{$\mathrm{CO}^{1}$} & $\mathrm{~N}$ & $\mathrm{P}_{2} \mathrm{O}_{5}$ & $\mathrm{~K}_{2} \mathrm{O}$ & $\mathrm{Ca}$ & $\mathrm{Mg}$ & $\mathrm{sS}$ & MOS & COT & $\mathrm{Na}$ & B & $\mathrm{Cu}$ & $\mathrm{Fe}$ & $\mathrm{Mn} \mathrm{Zn}$ & $\mathrm{C} / \mathrm{N}$ & Umi. & $\mathrm{pH}$ \\
\hline & - & 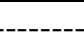 & 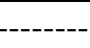 & 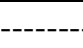 & ------ & ---- & $\overline{\mathrm{g} \mathrm{K}}$ & 1 & 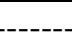 & 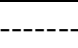 & 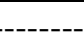 & 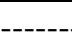 & - & & $\%$ & $\mathrm{H}_{2} \mathrm{O}$ \\
\hline $\mathrm{C}^{2}$ & 9,03 & 3,65 & 1,45 & 7,23 & 2,56 & 2,40 & 251,61 & 139,78 & 0,35 & 0,06 & 0,03 & 11,60 & $0,270,09$ & $16 / 1$ & 21,37 & 5,6 \\
\hline $\mathrm{H}^{3}$ & 13,49 & 5,50 & 17,09 & 7,73 & 3,46 & 3,18 & 334,12 & 185,62 & 1,34 & 0,04 & 0,02 & 7,15 & $0,780,07$ & $14 / 1$ & 22,30 & 6,0 \\
\hline
\end{tabular}

Resultados expressivos também foram apontados por Maranho e Paiva (2012) [17], trabalhando na produção de mudas de pau de rosa (Physocalymma scaberrimum) quando obtiveram maiores alturas de mudas produzidas com substrato a partir de $100 \%$ de composto com resíduos orgânico da despolpa de açaí, até a formulação de 50\% de resíduo, misturado a 50\% de terra de mata.

$\mathrm{Na}$ Tabela 4 está sendo representado o resumo da análise de variância para todos os atributos estudados, onde observa-se efeito significativo a $1 \%$ de significância para todas as variáveis estudadas para os diferentes tratamentos aplicados. Também foi evidenciado diferença significativa entre os blocos para as variáveis DC, H, MSPA e MFPA.

Tabela 4: Resumo da análise de variância obtido a partir da avaliação de 7 substrato em mudas de Biribazeiro em Humaitá, AM.

\begin{tabular}{|c|c|c|c|c|c|c|c|c|c|c|c|}
\hline \multirow{3}{*}{ FV } & \multirow{3}{*}{ GL } & \multicolumn{10}{|c|}{ 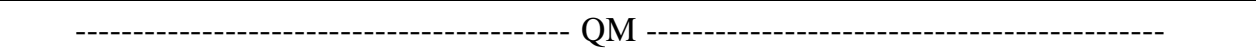 } \\
\hline & & DC & \multirow[b]{2}{*}{ NF } & $\mathrm{H}$ & $\mathrm{CR}$ & MSR & MFR & MSPA & MFPA & \multirow[b]{2}{*}{ IQD } & \multirow{2}{*}{ H/DC } \\
\hline & & $\begin{array}{c}\mathrm{mm} \\
\text { planta }^{-1}\end{array}$ & & $--\mathrm{cm} \mathrm{pl}$ & $\operatorname{lanta}^{-1}--$ & \multicolumn{4}{|c|}{-------- g planta-1 -------- } & & \\
\hline Tratamento & 6 & $7,11 * *$ & $77,98 * *$ & $186,07 * *$ & $340,05 * *$ & $0,24 * *$ & $4,47 * *$ & $1,05^{* *}$ & $1,70^{* *}$ & $3,86 \times 10^{-2 *:}$ & $10,04 * *$ \\
\hline Blocos & 3 & $1,53^{*}$ & $10,82^{\text {ns }}$ & $45,83 * *$ & $10,26^{\mathrm{ns}}$ & $0,03^{\mathrm{ns}}$ & $1,74^{\mathrm{ns}}$ & $0,21 *$ & $4,05^{*}$ & $6,21 \times 10^{-3 n s}$ & $1,64^{\mathrm{ns}}$ \\
\hline Resíduo & 18 & 0,32 & 3,75 & 8,55 & 23,75 & 0,02 & 0,59 & 0,06 & 0,98 & $2,30 \times 10^{-3}$ & 0,98 \\
\hline CV\% & - & 18,95 & 26,16 & 18,33 & 23,13 & 39,32 & 47,38 & 37,01 & 39,19 & 32,42 & 20,53 \\
\hline
\end{tabular}

*Significativo, pelo teste F, a $5 \%$ de probabilidade; ** Significativo pelo teste $\mathrm{F}$ a $1 \%$ de probabilidade.

De acordo com a Figura 1, pode-se observar que no $28^{\circ}$ dia o T4 foi superior aos demais tratamentos apresentando os melhores desempenhos nos parâmetros de diâmetro do caule, número de folhas e altura, já o T7 apresentou os menores valores após 28 dias de avaliação, chegando a próximo de zero, provavelmente devido a deficiência do nutriente $\mathrm{K}$, comprovado na Tabela 3 na compostagem onde apresentaram teores baixos desse nutriente. As plantas observadas apresentaram uma clorose seguido de necrose que se iniciou nas pontas das folhas mais velhas até 
o pecíolo, resultado similar foi diagnosticado por Rozane e Natale (2014) [18], estudando calagem e adubação mineral em anonáceas.
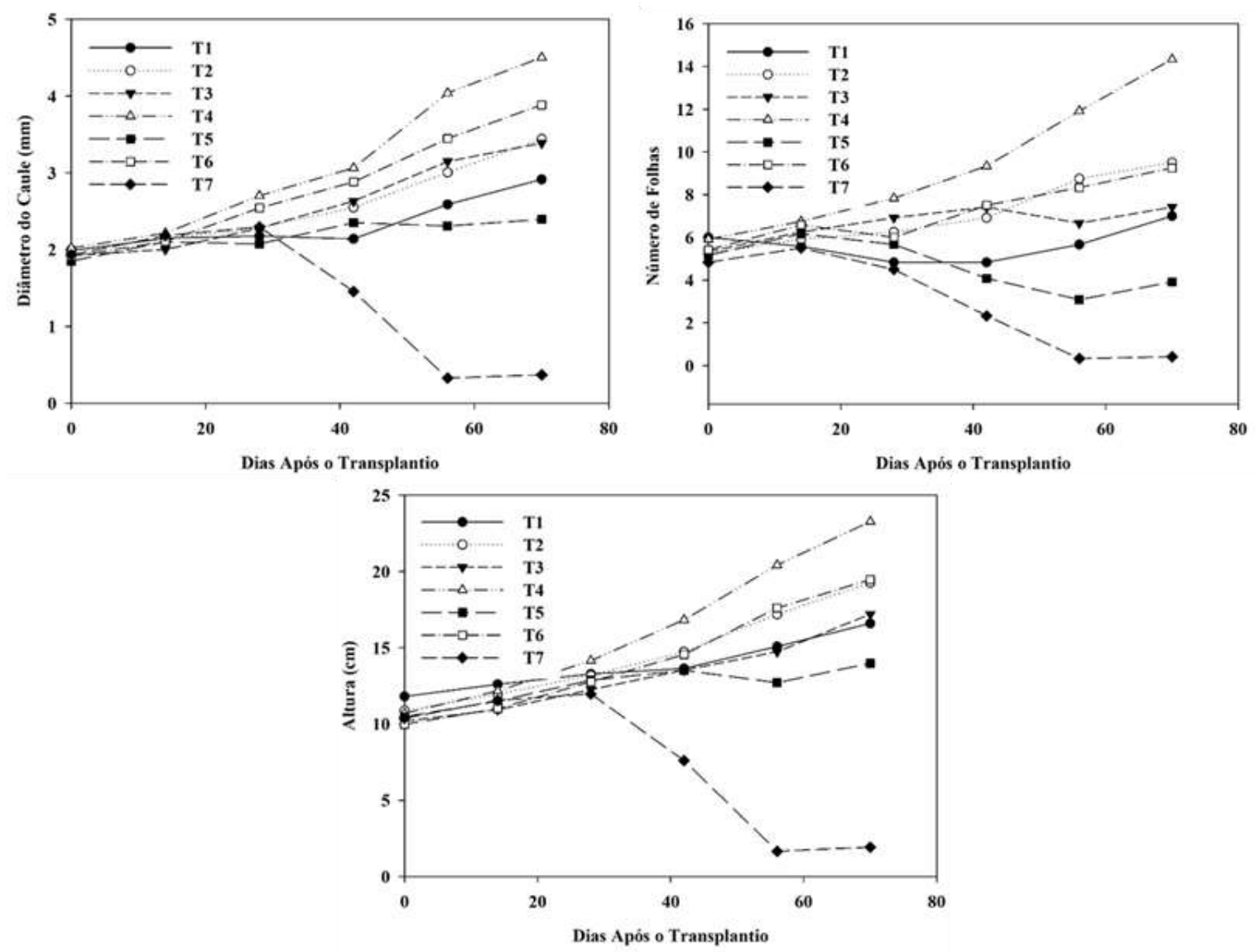

Figura 1: Crescimento em diâmetro do caule, número de folhas e altura de mudas de biribazeiro, submetidas a diferentes substratos no período de 70 dias, no município de Humaitá, AM.

O K é um nutriente ativador de diversas enzimas, sua deficiência ocasiona distúrbios em reações metabólicas de acumulação de compostos livres ou solúveis. Nas anonáceas, são importantes na fase inicial do crescimento de plântula até seu período de produção, o elemento K faz-se presente na composição de enzimas e de outros fotoassimilados no decorrer do desenvolvimento da planta [19].

O diâmetro de caule é um importante parâmetros de qualidade de mudas. Plantas com baixo diâmetro, mostram dificuldades em permanecer eretas pós-plantio em campo, podendo resultar em deformações e até morte. Entretanto, quando exibem maiores diâmetros dentro de uma mesma espécie, têm sua formação e novas raízes mais desenvolvidas e maior sobrevivência [20, 21], conforme Tabela 5 e Figura 1, mostrando maiores valores de DC, CR, MSR e MFR para o T4 com maiores teores de macronutrientes (Tabela 3), sendo esses fundamentais para o crescimento vegetativo da planta.

Quanto ao número de folhas por planta, a T4 apresentou o maior resultado diferindo estatisticamente dos demais tratamentos. Em relação à MSPA e MFPA, obteve-se o maior valor com o T4 que não diferiu significativamente do T6 sendo que o mesmo não diferiu significativamente dos demais tratamento com exceção do T7 que apresentou valores baixos. Wagner Júnior et al. (2006) [22], ao avaliarem, substratos na formação de mudas de Annona squamosa L. observaram relação proporcional entre o NF e a MSPA das plantas entre os tratamentos, sendo essa relação também observada no presente trabalho, onde demostra maiores valores de MSPA para os tratamentos que tiveram maiores NF (Tabela 5).

O número de folhas é um fator inteiramente ligado ao desenvolvimento da planta, por ser o principal órgão que faz fotossíntese, contribuindo, para formação de tecidos, fonte de auxina reservas de nutrientes e cofatores de enraizamento que são translocados para as raízes [16, 23]. 
Na Tabela 5 pode-se observar que o $\mathrm{T} 4$ resultou os maiores valores médios para as variáveis $\mathrm{CR}$, MSR, MFR, MSPA e MFPA. Para a variável CR o T4 não deferiu estatisticamente dos tratamentos T1, T2, T3 e T6 mas deferiu estatisticamente dos tratamentos T5 e T7, esses valores maiores de CR deve-se a maior disponibilidade dos nutrientes presente no húmus. As variáveis MSR, MFR, MSPA e MFPA, presente no T4 não deferiram estatisticamente do T6 deferindo dos demais tratamentos. Podemos relacionar esse aumento na MFPA e MSPA ao NF que favoreceu maior armazenamento de fotoassimilados pela parte aérea da planta [24] e pelo maior CR, MSR e MFR que proporcionou maior absorção de nutrientes para as plantas. Segundo Larcher (2000) [25], grande parte da biomassa acumulada pelas plantas durante o crescimento é resultado da atividade fotossintética e da absorção de nutrientes do meio.

Tabela 5: Valores médio obtido a partir da avaliação de 7 substrato em mudas de Biribazeiro no município de Humaitá, AM.

\begin{tabular}{|c|c|c|c|c|c|c|c|c|c|c|}
\hline \multirow{2}{*}{ Tratamentos } & $\mathrm{DC}$ & \multirow{2}{*}{ F } & $\mathrm{H}$ & $\mathrm{CR}$ & MSR & MFR & MSPA & MFPA & \multirow{2}{*}{ IQD } & \multirow{2}{*}{$\mathrm{H} / \mathrm{DC}$} \\
\hline & $\mathrm{mm} \mathrm{p}$ & & \multicolumn{2}{|c|}{-- cm planta ${ }^{-1}$-- } & \multicolumn{4}{|c|}{--------- g planta ${ }^{-1}$--------- } & & \\
\hline 1 & & & $16,59 \mathrm{ab}$ & $24,72 \mathrm{ab}$ & $0,21 \mathrm{~cd}$ & $0,90 \mathrm{c}$ & $0,42 \mathrm{~cd}$ & $1,51 \mathrm{bc}$ & & $5,70 \mathrm{a}$ \\
\hline & & & & & & & & & & $50 \mathrm{a}$ \\
\hline $\mathrm{T}$ & & $7,42 \mathrm{bc}$ & 17,2 & 23 & $0,28 \mathrm{bcd}$ & $1,48 \mathrm{bc}$ & & $2,53 \mathrm{bc}$ & & $5,09 \mathrm{a}$ \\
\hline $\mathrm{T}$ & & 14,3 & 23, & a & $3 \mathrm{a}$ & 3 , & a & $5,66 \mathrm{a}$ & & $5,18 \mathrm{a}$ \\
\hline $\mathrm{T}$ & & 3,9 & $\mathrm{~b}$ & $\mathrm{~b}$ & $\mathrm{~cd}$ & 1,0 & $\mathrm{~cd}$ & $1,48 \mathrm{bc}$ & $\mathrm{cd}$ & $5,85 \mathrm{a}$ \\
\hline T6 & . & $9,25 \mathrm{~b}$ & $19,47 \mathrm{ab}$ & $28,69 \mathrm{a}$ & $\mathrm{ab}$ & $2,70 \mathrm{ab}$ & $a b$ & $3,57 \mathrm{ab}$ & $0,23 \mathrm{ab}$ & $5,04 \mathrm{a}$ \\
\hline 7 & $0,37 \mathrm{~d}$ & $0,42 \mathrm{~d}$ & $1,93 \mathrm{c}$ & $2,85 \mathrm{c}$ & $0,04 \mathrm{~d}$ & $0,27 \mathrm{c}$ & $0,07 \mathrm{~d}$ & $0,40 \mathrm{c}$ & $0,02 \mathrm{~d}$ & $1,30 \mathrm{~b}$ \\
\hline
\end{tabular}

Letras iguais minúsculas na coluna não diferem estatisticamente entre si pelo teste Tukey ao nível de $5 \%$ de probabilidade $(\mathrm{p}<0,05)$.

O P é o principal nutriente-chave na fase inicial de crescimento das plantas, devido ao maior acúmulo de biomassa requerido nesta fase [22]. Ele influencia, na emissão e no tamanho das folhas, estimulando o crescimento da parte aérea das plantas [26]. Observou-se maiores teores de P no composto orgânico húmus e consequentemente maiores valores de NF, DC, H, MSPA e MSPA para o T4 que utilizou 50\% de solo e 50\% de húmus (Figura 1 e Tabela 5) parâmetros esses que mostraram valores maiores que os encontrados por Wagner Júnior et al. (2006) [22], que estudou substratos na formação de mudas de pinheira.

Para variável altura de planta foi encontrado maior valor para o tratamento T4 que estatisticamente não deferiu dos tratamentos T1, T2, T3 e T6 deferindo apenas dos tratamentos T5 e T7 (Tabela 5). Considerando que o $\mathrm{N}$ é nutriente essencial para o desenvolvimento das células meristemáticas [27], a baixa concentração deste pode influenciar no desenvolvimento em altura das plantas. Valores esses observados na Figura 1 e Tabela 5 para os tratamentos T5 e T7, que utilizou a compostagem na formulação do substrato, sendo que a mesma apresentou baixo teor de $\mathrm{N}$ (Tabela 2).

O tratamento T5 apresentou maior valor para a relação altura e diâmetro do caule (H/DC), entretanto não deferiu estatisticamente dos demais tratamentos, exceto para o T7. Ao avaliar a relação H/DC podemos determinar a qualidade das muda a serem levadas ao campo [28], pois plantas com relação H/DC elevada apresentam dificuldades de se manterem eretas após o plantio, entretanto, quando apresentam menor valor da relação H/DC implica mudas mais resistentes no campo [29].

O índice de qualidade de Dickson (IQD) variou de 0,02 a 0,31 para os tratamentos T7 e T4 respectivamente, onde o T4 apresentou o maior valor, entretanto, não deferiu estatisticamente do T6 que deferiu estatisticamente dos demais tratamentos. Os valores de IQD dos tratamentos T4 e T6 ficaram acima de 0,2, que, segundo Gomes e Paiva (2006) [30], é considerado o valor mínimo para definir o melhor padrão de qualidade das mudas. Porém, diversos estudos mostram que o IQD é uma variável mutável, sendo influenciada pela espécie, manejo, tipo de substrato, tamanho do recipiente e idade em que a muda foi avaliada [21]. Fonseca et al. (2002) [31], ressaltam que, é importante utilizar o IQD para avaliar a qualidade das mudas, por ser uma variável que leva em conta o equilíbrio da distribuição da biomassa das mudas. 


\section{CONCLUSÃO}

Os melhores resultados para todas as variáveis avaliadas foram obtidos com o tratamento 4 utilizando $50 \%$ de solo e $50 \%$ de húmus.

O tratamento 7 utilizando $25 \%$ de solo $50 \%$ de compostagem e $25 \%$ de areia apresentou deficiência de K, causando clorose e necrose nas plantas, não propiciando crescimento satisfatório.

$\mathrm{O}$ húmus apresentou maiores teores de macro e micronutrientes em relação a compostagem.

\section{REFERÊNCIAS BIBLIOGRÁFICAS}

1. Manica I. Frutas nativas, silvestres e exóticas. 1nd ed. Porto Alegre: Cinco Continentes Editora, 2000. $327 \mathrm{p}$.

2. Braga Sobrinho R. Produção Integrada de anonáceas no Brasil. Revista Brasileira de Fruticultura. 2014 Fev;36:102-107. doi: 10.1590/S0100-29452014000500012

3. Santos CE, Roberto SR, Martins ABG, Propagação do biribá (Rollinia mucosa) e sua utilização como porta-enxerto de pinha (Annona squamosa). Acta Sci Agron. 2005 Set;27(3):433-436, doi: 10.4025/actasciagron.v27i3.1404

4. Ferreira MGR, Santos MRA, Silva EO, Gonçalves EP, Alves EU, Bruno RDLA. Emergência e crescimento inicial de plântulas de biribá (Rollinia mucosa (Jacq.) Baill) (Annonaceae) em diferentes substratos. Semina: Ci Agr. 2010 Jun;31(2):373-380, doi: 10.5433/1679-0359.2010v31n2p373

5. Paiva JRG, Silva F, Ferreira LL, Mesquita EF, Porto VCN. Produção de mudas de pinheira (Annona Squamosa L.) em função da adubação orgânica e volumes de substrato. Cadernos Agroecol. 2013 Dez;8(2).

6. Brasil EC, Nascimento EVS. Influência de calcário e fósforo no desenvolvimento e produção de variedades de maracujazeiro-amarelo. Rev Bras Frutic. 2010 Mai;32(3):892-902, doi: 10.1590/S010029452010005000092

7. Kämpf AN. Produção comercial de plantas ornamentais. Guaíba: Agropecuária, 2000. 254 p.

8. Erlacher WA, Oliveira FL, Silva DMN, Quaresma MAL, Mendes TP. Estratégias de uso de caroço de açaí para formulação de substratos na produção de mudas de hortaliças. Magistra. 2016 Mar;28(1):119130.

9. Teixeira LB, Oliveira RF, Furlan JJ, Cruz ES, Germano VLC. Processo de compostagem a partir de lixo orgânico urbano e caroço de açaí (Circular Técnica, N. 105, 4p) Belém: Embrapa Amazônia Oriental. 2004.

10. BRASIL. Ministério das Minas e Energia. Projeto Radambrasil - Folha SB. 20, Purus. Rio de Janeiro, 1978. 561p.

11. Dickson A, Leaf AL, Hosner JF. Quality appraisal of white spruce and white pine seedling stock in nurseries. Forest Chron. 1960 Set;36(1):10-13, doi: 10.5558/tfc36010-1

12. Silva FAS, Azevedo CAV. The Assistat Software Version 7.7 and its use in the analysis of experimental data. Afr J Agric Res. 2016 Set;11(39):3733-3740, doi: 10.5897/AJAR2016.11522

13. Ribeiro AC, Guimrães PTG, Alvarez VVH. Recomendações para uso de corretivos e fertilizantes em Minas Gerais - 5a Aproximação. Viçosa, Universidade Federal de Viçosa, 1999, p.25 - 30.

14. Eastman BR. Achieving pathogen stabilization using vermicomposting: Spiking the biosolids. BioCycle. 1999;40(11):62-64.

15. Corrêa RS, Fonseca TM, Corrêa AS. Produção de biossólido agrícola por meio da compostagem e vermicompostagem de lodo de esgoto. Rev Bras Eng Agríc Amb. 2007 Abr;11(4):420-426, doi: 10.1590/S1415-43662007000400012

16. Taiz L, Zeiger E. Fisiologia vegetal. 5. ed. Porto Alegre: Artmed Editora S. A. 2013.

17. Maranho AS, Paiva AV. Produção de mudas de Physocalymma scaberrimumem substratos compostos por diferentes porcentagens de resíduo orgânico de açaí. Floresta. 2012 Fev;42(2):399-408, doi: 10.5380/rf.v42i2.19220

18. Rozane DE, Natale W. Calagem, adubação e nutrição mineral de Anonáceas. Rev Bras Frutic. 2014 Fev;36:166-175, doi: 10.1590/S0100-29452014000500020

19. São José AR, Prado NB, Bomfim MP, Rebouças TNH, Mendes HTA, Marcha de absorção de nutrientes em anonáceas. Rev Bras Frutic. 2014 Fev;36:176-183, doi: 10.1590/S0100-29452014000500021

20. Souza CAM, Oliveira RB, Martins Filho S, Lima JS. Desenvolvimento em campo de espécies florestais em diferentes condições de adubação. Ciênc Florest. 2006 Jun;16(3):243-249, doi: $10.5902 / 198050981905$

21. Marinho PHA, Souza RM, Giongo M, Viola MR, Souza PB. Influência de diferentes substratos na produção de mudas de flamboyant Delonix regia (Bojer ex Hook.) Raf. Rev Agro@mbiente On-line. 2017 Mar;11(1):40-46, doi: 10.18227/1982-8470ragro.v11i1.3870 
22. Wagner Júnior A, Neres CRL, Silva Negreiros JR, Alexandre RS, Diniz ER, Pimentel LD, Bruckner CH. Substratos na formação de mudas de pinheira (Annona squamosa L.). Rev Ceres. 2006 Ago;53(308):439445, http://www.locus.ufv.br/handle/123456789/13109

23. Araújo AP, Paiva SP. Germinação e produção de mudas de tamboril (Enterolobium contortisiliquum (Vell.) Morong) em diferentes substratos. Rev Árvore. 2011 Abr;35(3):581-588, doi: 10.1590/S010067622011000400001

24. Silva JG, Oliveira OH, Nobre RG. Produção de mudas de gravioleira sob métodos de superação de dormência de sementes e doses de esterco. Rev Verde Agroecologia Desenvolv Sustent. 2017 jun;12(2):187-191, doi: 10.18378/rvads.v12i2.4649

25. Larcher W. Ecofisiologia Vegetal. São Carlos, Rima. 2000, 531p.

26. Negreiros H, Braga L, Álvares V, Bruckner C. Diferentes substratos na formação de mudas de mamoeiro do grupo solo. Rev Bras Agrociênc. 2005 Mar;11(1):101-104, doi: 10.18539/CAST.V11I1.1168

27. Leonardo FAP, Oliveira AP, Pereira WE, Silva POR, Barros JRA. Rendimento da batatadoce adubada com nitrogênio e esterco bovino. Rev Caatinga. 2014 Jun;27(2):18-23.

28. Viana JS, Gonçalves EP, Andrade LA, Oliveira LSB, Silva EO. Crescimento de mudas de Bauhinia forficata Link em diferentes tamanhos de recipientes. Floresta. 2008 Dez;38(4):663-671, doi: 10.5380/rf.v38i4.13161

29. Aguiar FFA, Kanashiro S, Tavares AR, Nascimento TDR, Rocco FM. Crescimento de mudas de paubrasil (Caesalpinia echinata Lam.), submetidas a cinco níveis de sombreamento. Ceres. 2011 Dez;58(6):729-734, doi: 10.1590/S0034-737X2011000600008

30. Gomes JM, Paiva HN. Viveiros florestais: propagação sexuada. Viçosa: UFV, 2006.

31. Fonseca EP, Valéri SV, Miglioranza E, Fonseca NAN, Couto L. Padrão de qualidade de mudas de Trema micrantha (L.) Blume, produzidas sob diferentes períodos de sombreamento. Rev Árvore. 2002 Jun;26(4):515-523, doi: 10.1590/S0100-67622002000400015 